Kansas State University Libraries

New Prairie Press

\title{
UTILIZATION OF THE LINE-INTERCEPT METHOD TO ESTIMATE THE COVERAGE, DENSITY, AND AVERAGE LENGTH OF ROW SKIPS IN COTTON AND OTHER ROW CROPS
}

Jeffrey L. Willers

Sreenivasa R. Yatham

Michael R. Williams

Dennis C. Akins

See next page for additional authors

Follow this and additional works at: https://newprairiepress.org/agstatconference

Part of the Agriculture Commons, and the Applied Statistics Commons (c) (1) $(9)$

This work is licensed under a Creative Commons Attribution-Noncommercial-No Derivative Works 4.0 License.

\section{Recommended Citation}

Willers, Jeffrey L.; Yatham, Sreenivasa R.; Williams, Michael R.; and Akins, Dennis C. (1992). "UTILIZATION OF THE LINE-INTERCEPT METHOD TO ESTIMATE THE COVERAGE, DENSITY, AND AVERAGE LENGTH OF ROW SKIPS IN COTTON AND OTHER ROW CROPS," Conference on Applied Statistics in Agriculture. https://doi.org/10.4148/2475-7772.1394

This is brought to you for free and open access by the Conferences at New Prairie Press. It has been accepted for inclusion in Conference on Applied Statistics in Agriculture by an authorized administrator of New Prairie Press. For more information, please contact cads@k-state.edu. 
Author Information

Jeffrey L. Willers, Sreenivasa R. Yatham, Michael R. Williams, and Dennis C. Akins

This is available at New Prairie Press: https://newprairiepress.org/agstatconference/1992/proceedings/6 


\title{
UTILIZATION OF THE LINE-INTERCEPT METHOD TO ESTIMATE THE COVERAGE, DENSITY, AND AVERAGE LENGTH OF ROW SKIPS IN COTTON AND OTHER ROW CROPS
}

\author{
by \\ Jeffrey L. Willers, Sreenivasa R. Yatham, Michael R. Williams \\ and Dennis C. Akins \\ USDA, ARS, Crop Simulation Research Unit, \\ Mississippi State, Mississippi
}

\begin{abstract}
$\underline{\text { Abstract }}$
In row crops, a skip is a length of row within the drill where the crop has failed to establish. If the number of skips and their mean length per acre becomes too high, then considerable losses in crop yield occur. Frequently, farmers are faced with the decision to replant a crop which has row skips. To make the best decision, reliable estimates of the stand loss due to skips must be available. In making this decision, three parameters are useful: the percent of the area per acre that is skipped, the number of individual skips (that is, density) per acre, and the mean row length per skip. The line-intercept method for the sampling of two-dimensional objects (particles) can be used to obtain estimates of these parameters. The method is illustrated with an example from a cotton field.
\end{abstract}

Keywords: Cotton, coverage, line-intercept, plant stand, replanting decisions, row crops, sampling, skips.

\section{Introduction}

Every year farmers are faced with many decisions with respect to the crops they have planted. After the crop has emerged, one of the first decisions is whether or not the emerged stand is adequate to produce a good yield. Weather, disease, insects or other causes can damage or destroy seedling plants causing skips, or gaps, to occur within the rows. If the percentage of the crop lost is too high, a decision must be made to replant. This decision must be timely, for delays in planting may cause the complete loss of even the replanted stand. On the other hand, if the crop is replanted when it is not necessary to do so, then additional costs in seed, agri-chemicals, time and equipment are wasted.

The question then becomes, "Should that field where the stand has skips be replanted?". Agronomists have proposed guidelines to help farmers make this decision. In cotton, for example, McCarty (1989) has written that some important considerations in deciding to replant are: plant distribution down the drill (that is, number of plants per row foot and their distribution), the number of large skips in the drill, and plant number (that is, density per acre). These considerations define several 
criteria that a producer has to evaluate. In a later article, McCarty (1991) provided suggestions on what values these parameters should exceed before the crop is replanted. For a cotton field which has conventional row spacings (that is, solid planted cotton with 38 " between the drills), the plants should be uniformly distributed and average 2 to 4 plants per row foot. If skips are present, then one should become concerned when they average $6 \mathrm{ft}$ or more in length, are adjacent to each other on adjoining rows, and the stand is reduced more than 25 percent. At a stand loss of 25 percent, a 16 percent yield loss is expected.

Given these guidelines, how does one obtain the estimates necessary to reach a decision? An objective measure upon which to base this decision is necessary. A search of the literature turned up little on how to obtain and analyze the necessary data; however, see Nielsen (1991) for a discussion of the problem in corn. A solution to this problem is to use the line-intercept method for sampling two-dimensional objects (particles). The line-intercept method is well suited for obtaining the necessary information for making replanting decisions. The method is not laborious to apply in row crops and is advantageous in its simplicity. Three statistics supplied by its use correspond to several agronomic guidelines: the percent of the area per acre that is skipped (that is, coverage), the number of individual skips (that is, density) per acre, and the mean row length per skip. Using these estimates, an informed decision can be made on whether or not to replant the crop.

The line-intercept sampling method for the sampling of any two-dimensional object has been widely used and has a long history, particularly in the forestry and wildlife sciences (Kaiser 1983; Warren and Olsen 1964; Van Wagner 1968). We have not found, however, any reference to its use in cotton, or other row-crops. We demonstrate its use in a commercial cotton field during the 1991 production season.

\section{Terminology}

\section{Methodology}

According to Eberhart (1978), transect methods can be apportioned into 3 common categories. The first type, the line-intercept technique discussed here, involves the interception of two-dimensional objects by a one-dimensional line. With this method, the purpose of the sample, or census method, is to estimate the number of objects in a specified area of study, and the fraction of the study area occupied by these objects. This fraction is called coverage (Eberhart 1978; Lucas and Seber 1977; McDonald 1991). In row crops, when skips in the drill are the objects, coverage is also known as percent stand loss. The method can also be used to estimate other attributes besides coverage or density (Kaiser 1983; McDonald 1980). In this study, the attribute to be measured is the mean length of the skip.

The other two transect categories are known as the strip-transect and the linetransect methods. With these applications, the objects encountered by a "line" are considered dimensionless. Either the line has dimension (the strip-transect) or attributes of the objects are recorded in reference to their position, distance, or radius 
to the line (the line-transect). However, as Eberhart (1978) remarks, these three categories are not mutually exclusive.

The terminology and notation of McDonald $(1980,1991)$ can be adopted for row crop applications. Figures 1 and 2 diagram the use of many of the necessary symbols. The intercepted object is the skip within the drill. The drill is centered between two furrows. The length of the skip bisects the drill and is the distance between (cotton) plants on each end of the skip. The length of the intersection of the transect line and the skip is the distance between furrows, or the crop's row spacing. Thus, the row spacing is the width of the skip "object".

The following symbols apply for line-intercept parameters. Let: $A$ represent the area of the study region, $y_{\mathrm{i}}$ be the attribute of interest to be measured on the $i$ th intercepted skip, $N$ be the number of individual skips in $A, Y$ be the sum total of attribute $y$ over all skips, $\mu_{y}$ be the mean of the $y$ th attribute for the skip, and $C$ be the coverage by the $N$ skips in $A$.

The corresponding statistics, and their symbols, can also be defined (McDonald 1980, 1991). Let: $L$ be the length of a randomly located transect line on a baseline of length $W, v_{i}$ be the length of the intersection of the transect line and the $i$ th skip, $w_{i}$ be the length of the projection of the $i$ th skip on the baseline. Specifically, this is the length of the skip in the row (Fig. 1). Finally, let $n$ be number of individual skips intercepted by the transect line $(i=1,2,3, \ldots, n)$. The statistic $w_{i}$ is constrained to have a minimum value of $3 \mathrm{ft}$, and a maximum value of $W$, the baseline length.

The baseline is the base, or one side of the (rectangular) study area. The units of measure for distance are feet, to nearest tenth of a foot, while area is expressed in acres. It is convenient to let each sampled area be 1.0 acre in size. Therefore, a study area's size can be defined by the baseline and transect line lengths $(A=W x L)$.

Also, the baseline is a reference line which runs perpendicular to the transect line, but parallel to the row direction (Fig. 2). The baseline lies in the furrow, midway between two adjacent rows. The baseline length and its location within the field defines the study area. It is suggested that at least four baselines be placed within each 50-100 acre block of a field. Within these blocks, the baseline's origins are selected at random. To save time, in practice, it would be best to choose these origins using a systematic randomization scheme. It is important to randomly select the baseline origins, for as Steel and Torrie (1960) point out, haphazard selection is not random. Similarly, the origins of each transect line on these baselines can be assigned by a second systematic randomization scheme. In particular, the randomization schemes should guarantee that the study areas do not overlap. If they overlap, the transect lines cannot be independent samples (Anderson et al. 1979).

When collecting a sample, the observer first locates a baseline's origin and then moves to the point on that baseline where the transect line begins. The transect line runs perpendicular to the baseline for a distance of 32 rows (Fig. 2). Recorded are the 
lengths of each skip ( $3 f t \leq w_{i} \leq W f$ ) intercepted by the transect line as the observer walks across the rows. It only takes a few minutes to walk one of these transect lines, but the actual time required will vary according to the number of skips intercepted.

\section{$\underline{\text { Formulae }}$}

The formulae used to estimate the parameters for coverage, density, and mean skip length are reported here for a crop with a row spacing of $38 \mathrm{in}$. Thus, a baseline $430 \mathrm{ft}$ long with a transect line 32 rows long defines a study area $(A)$ of 1.0003 acre $\left(43,573.333 f^{2}\right)$, or 1 acre for practical purposes. For crops that have different row spacings appropriate adjustments in formula constants would be necessary.

To estimate the number of skips per acre (density) the following formula applies:

$$
\hat{N}=W \sum_{i=1}^{n}\left(1 / w_{i}\right)
$$

where $W$ is $430 \mathrm{ft}$, the baseline length. The general formula for the mean skip length per acre is:

$$
\hat{\mu}_{Y}=\left(\sum_{i=1}^{n}\left(y_{i} / w_{i}\right)\right) /\left(\sum_{i=1}^{n}\left(1 / w_{i}\right)\right)
$$

and when sampling for skips, specifically, the attribute $y_{i}=w_{i}$. Coverage is defined by:

$$
\hat{C}=\sum_{i=1}^{n} v_{i} / L=\frac{\hat{N} \hat{\mu}_{Y}}{13756}
$$

and $L$ is a constant, $101.34 \mathrm{ft}$ ( 32 rows multiplied by the row spacing of $3.167 \mathrm{ft}$ ).

The term $v_{i}$ can also be a constant whenever adjacent rows do not have skips (Fig. 1). If adjacent rows intercepted by the transect line have skips, then the $i$ th term in the numerator of eq. (3) can be some multiple of the row spacing. This multiplier will be the number of adjoining rows in the cluster which have skips. Coverage can also be obtained by multiplying the skip density per acre by the mean length per skip, and dividing by the number of linear row feet per acre. This number will be 13,756 linear row feet for 38 in row spacings.

\section{Background on Example}

The data for the example were obtained from a 50 acre portion of a 200 acre cotton field grown in Leflore County, Mississippi. Within this portion, the skips were the result of heavy rains that preceded and followed the planting of the crop. When 
the stand emerged, the owner of the field decided, subjectively, that the stand was too skimpy and that he should replant. However, time did not permit this to be done and the field remained as it was until harvest. Other agronomic practices were performed on schedule and were similar to those practiced on the rest of the field, which was planted later, and did not have skips.

In this study, a baseline was placed in each of 4 adjacent 1 acre plots in the 50 acre area. Four different observers, walked along a different transect line on each baseline. Each observer had the same random starting distance for their transect on these baselines. Each observer measured and recorded the length of each intercepted skip if that skip was $\geq 3 f t$ in length. For each observer the baseline is the unit of replication. The transect line is the basic sample unit. These baselines were adjacent to one another to simplify the obtainment of absolute counts to be used for validation. In actual applications the baselines will not be adjacent, and the statistics obtained by an observer will be used to infer the status of the rest of the field.

Absolute counts were obtained from the same half of each of the four sampled acreages. These counts permit the comparisons of sample estimates for coverage, density and average length of skip to those actually present. These numbers, after the completion of any necessary normalization steps, are the parametric values used for hypothesis testing.

For each observer, statistics were calculated for skip density, mean skip length, and coverage for each sample line. The data were analyzed using a one-way treatment structure in a completely random design. Levene's test was used to test for homogeneity of variances (Milliken and Johnson 1984) for the three measures. Tests of hypotheses were performed by forming linear combinations of sample means (Milliken and Johnson 1984), and testing for either equality among means or the equivalence of means to some hypothesized value. These values are the parametric counts previously described for skip density, length and coverage. This approach based upon the $F$-test is easily applied to these data.

Two questions of interest in this study are (1) Did any observer differ significantly from any other observer in their estimate for coverage, density, and mean skip length, and (2) Do the observers differ significantly from the parametric values for these quantities? The first question can be stated in the form of the following hypothesis:

$$
\mathrm{H}_{0}: \mu_{1}=\mu_{2}=\mu_{3}=\mu_{4} \quad \text { (4) }
$$

The second question can be stated by forming linear combinations of sample means (Milliken and Johnson 1984) of the form:

$$
\mathrm{H}_{0}:\left(\mu_{1}+\mu_{2}+\mu_{3}+\mu_{4}\right) / 4=a
$$


where $a$ is the parametric value for either coverage, density, or mean skip length. For both hypotheses, the $\mu_{j}$ 's are the observer $(j=1,2,3,4)$ means for these statistics.

If hypothesis (5) was rejected for any line-intercept statistic, then a $95 \%$ confidence interval was found for each observer's mean. This interval was then examined to see if $a$ was contained within that interval. If $a$ was not included, the conclusion was that the particular line-intercept statistic differed significantly from its parametric value.

\section{Results and Discussion}

From the absolute counts of skips, the parametric value for coverage was determined to be 8.8 percent, the density per acre was found to be 281 skips, and the mean skip length was $4.4 \mathrm{ft}$. Presented in Fig. 3 is a histogram of all the skips measured in one-half of the combined study areas. Skips at least $10 \mathrm{ft}$ or longer were combined into one class. The longest skip measured was $30 \mathrm{ft}$ with a frequency of one.

It would be instructive to know if any observer reached a different conclusion about the extent of skips in the cotton field just because a different random start was chosen for the placement of a transect line on a common baseline. This is the problem addressed by hypothesis (4). But, to test this hypothesis, it needs to be seen if the estimates obtained by the observers had similar or different variances. Levene's test can be used to test this assumption, since the sample sizes are small $\left(n_{i}=4\right.$, for $i$ $=1,2,3,4)$ and because the sample distributions are not likely to be normal.

Levene's test, with a significance level of $1 \%$, indicated that the variation in the four observers' estimates on skips were homogenous for density $(F=0.79$; $\mathrm{df}=3,12 ; P=$ $0.523)$, mean length $(F=2.48$; df $=3,12 ; P=0.111)$, and coverage $(F=4.74 ; \mathrm{df}=$ 3,$12 ; P=0.021$ ).

Of these three estimates, coverage was possibly the most doubtful in meeting the assumption of homogeneity of variance. A possible reason for this occurrence, suggested by an examination of the original census data, is that when skips occur together on adjacent rows, or there are a greater number of longer skips observed on one transect line than on other transect lines, coverage tends to increase. For example, one observer whose estimated average coverage was $18.0 \%$, had one transect line giving a coverage estimate of $31.25 \%$. This was the largest value observed for coverage among any of the 16 transect lines. This particular line had two clusters of skips, one having 3 and the other having 7 adjacent rows with skips. The effect of skips occurring in clusters, or of several skips longer than average occurring on a single transect has other influences as well.

To see what these additional influences are, we must examine the results of hypotheses which simultaneously compare several means to a single value. However, before these comparisons can be meaningful, a conclusion must be reached about the equality of the means (Hypothesis (4)). The conclusions were that the means (Table 
1) of the observers were equivalent for density $(F=0.70$; $\mathrm{d} f=3,12 ; P=0.570)$, mean length $(F=0.33$; df $=3,12 ; P=0.807)$, and coverage $(F=0.96 ; \mathrm{df}=3,12 ; P=$ 0.443 ). It can be concluded that the observers reached similar conclusions irrespective of where the transect line was placed on the baseline. This conclusion increases one's confidence in the suitability of the method for estimating parameters on row skips.

On the other hand, when we examine the results from simultaneously testing the equality of all means to a constant (Hypothesis (5)), it is seen that at least one of the four observers differed significantly from the others in his conclusions about density $(F=7.482 ; \mathrm{df}=1,12 ; \alpha=0.05)$ and coverage $(F=5.622 ; \mathrm{df}=1,12 ; \alpha=$ $0.05)$, but not significantly for mean skip length $(F=0.250 ; \mathrm{df}=1,12 ; \alpha=0.05)$. How can this be explained? We see that, after constructing $95 \%$ confidence intervals, the conclusions of only one of the four observers differed significantly from the others in parametric values of density and coverage. For this observer, the intervals did not contain the parametric value for either density $\left(294.66<\mu_{1}<813.18 ; a=281\right.$ skips/acre) or coverage $\left(10.153<\mu_{1}<25.785 ; a=8.8 \%\right.$ skips/acre). The reason for this observer's differences can be attributed to the same transect line discussed above which included two instances of skips in clusters. However, because each individual skip within these clusters did not differ significantly from the parametric skip length, there was no difference in the mean skip length for this transect line and the other 15 lines.

These results do not say that the line-intercept method is inappropriate for row crop applications involving skips. Rather, it further strengthens justification for its use. This is reasonable because, if a single transect line has an estimate different from other samples in a field, it indicates an area where different circumstances occur. It would be very practical in situations such as this to return to the field and obtain more samples in the vicinity of the discrepant line. Alternately, one could also employ a stratified sampling plan.

The results of this study suggest that for row crops, it is important to define a minimum skip length. The size of a skip can introduce a size bias into the estimates of skip density, mean skip length, or even other attributes (McDonald 1991). The size bias is apparent from eqs. (1) and (2), because one sums the reciprocals of the skip length, and the probability of encountering a skip is a function of its size. Size bias can be substantial, particularly for skips that are too small to be of agronomic importance. For example, during the analysis of one transect, a single $4 \mathrm{ft}$ length was improperly coded as a $0.4 \mathrm{ft}$ length. This error resulted in the number of skips to be calculated as 1,827 per acre. When the coding error was corrected, the estimate fell to 655 skips per acre. This is why the minimum skip length is defined to be $3 \mathrm{ft}$, and only skips $\geq 3 f t$ were measured and counted. Notice that this length is half the length of the agronomic guideline of $6 \mathrm{ft}$ (McCarty 1991).

This minimum skip length was chosen, after discussions with several cotton agronomists, who are of the opinion that skips of this size will not cause yield loss. Thus, by using a minimum skip distance that corresponds to zero yield loss, we have 
sought to correct for size bias arising from the sampling of skips that are too small. Further study may show, however, that a more optimal minimum skip length may some other value between 3 and

$6 \mathrm{ft}$.

Similarly, since the size of a skip cannot infinitely increase, the maximum permissible skip length was defined to be the baseline length $(W)$. This case can occur, for example, when a planter box fails to drop seed into the drill during one or more passes through the field. For any length of skip, however, correction for size bias may merit further study with extremely long skips, or when skips cluster together on several adjacent rows. It seems best, to group skips which occur in clusters separately from individual skips, because it can be argued that they belong to a different class of two-dimensional objects. These instances seem similar to the group size problem discussed by Samuel and Pollock (1981) for animals that occur in herds having different numbers of animals.

Kaiser (1983) and Lucas and Seber (1977) discuss variance estimation for lineintercept sampling. With line-intercept sampling the estimation of variance is a difficult problem. However, the use of the $F$-distribution provides a robust approach to hypothesis testing of line-intercept estimates in row crop applications, avoiding the difficulty in variance estimation. This use of the $F$-statistic is similar to McDonald's (1991) use of the $t$-statistic.

\section{Conclusions}

Unique features of row crops, such as the occurrence of parallel rows that are equally spaced, permit easy application of the line-intercept method. Thus, the method is likely to be used in practice because it is not laborious to apply. Further, the collection of observations along a randomly located linear transect, placed perpendicular to a baseline of known length, avoids bias in the selection of the sample by the observer. The line-intercept method more easily permits the selection of unbiased samples than other methods tried. This fact is a major justification for its use in row crops.

The final result for the cotton field used in this study was that, at harvest, the area of the field having skips yielded 100 pounds more of cotton lint than the rest of the field. The yield increase was the result of less competition for nutrients, water, and sunlight, permitting the plants with the skips to set and retain more cotton bolls than the plants in the more uniform stand. This is to be expected, since the estimates for coverage, density, and mean skip length were well below the guidelines proposed by McCarty (1991). If the weather had been more favorable this stand would have been replanted, with additional costs in time and money. If the method discussed here had been available, the decision to not replant would have been made. The decision would have been an informed one, instead of one reached by guesswork. This result illustrates that a judgement based upon observation alone, without systematic data collection and follow-up analysis can result in reaching a wrong conclusion. The line- 
intercept method demonstrated its usefulness in obtaining the necessary information for making better decisions about replanting a row crop.

The computational steps used to obtain the necessary estimates for coverage, density and mean skip length have been coded in the programming language $\mathbf{C + +}$. The program is facilitated with a user friendly interface, making it possible for farmers to apply the method to their own fields. The software is available upon request.

\section{$\underline{\text { Acknowledgments }}$}

We thank Drs. M. Boone, H. Hodges, J. Reed and other anonymous reviewers for their review and comments while the manuscript was in preparation. We also thank W. Nyquist for directing us to the stand establishment literature for corn. We express our appreciation to W. Bush for permission in allowing us to use the cotton field on Tupelo Plantation.

\section{$\underline{\text { References }}$}

Anderson, D. R., J. L. Laake, B. R. Crain and K. P. Burnham. 1979. Guidelines for Line Transect Sampling of Biological Populations. J. Wildl. Manage. 43: 70-78.

Eberhart, L. L. 1978. Transect Methods for Population Studies. J. Wildl. Manage. 42: $1-31$.

Kaiser, L. 1983. Unbiased Estimation in Line-Intercept Sampling. Biometrics 39: 965-976.

Lucas, H. A and G. A. F. Seber. 1977. Estimating Coverage and Particle Density Using the Line-Intercept Method. Biometrika 64: 618-622.

McCarty, W. 1989. Mississippi Cotton Crop Running Late. Delta Farm Press, Friday, May 26. p. 8.

McCarty, W. 1991. Cotton Situation Goes From Serious to Critical. Delta Farm Press, Friday, May 20. p. 9.

McDonald, L. 1980. Line-intercept Sampling for Attributes Other than Coverage and Density. J. Wildl. Manage. 44: 530-533.

McDonald, L. 1991. VIII. Line-intercept Sampling for Two-dimensional Particles, 트 Sampling of Biological Populations and Resource Selection Studies, Workshop Notes. University of Wyoming, Laramie.

Milliken, G. A. and D. E. Johnson. 1984. Analysis of Messy Data. Volume I: Designed Experiments. Van Nostrand Reinhold, New York. 473 pp. 
Neilsen, B. 1991. Stand Establishment Uniformity in Corn. Extension Publication AGRY-91-1, Purdue University, West Lafayette, Indiana.

Samuel, M. D. and K. H. Pollock. 1981. Correction of Visibility Bias in Aerial Surveys Where Animals Occur in Groups. J. Wildl. Manage. 45: 993-997.

Steel, R. G. D. and J. H. Torrie. 1960. Principles and Procedures of Statistics, with Special Reference to the Biological Sciences. McGraw-Hill, New York. 481 pp.

Van Wagner, C. E. 1968. The Line-Intersect Method In Forest Fuel Sampling. For. Sci. 14: 20-26.

Warren W. G. and P. F. Olsen. 1964. A Line-Intersect Technique for Assessing Logging Waste. For. Sci. 10: 267-276. 


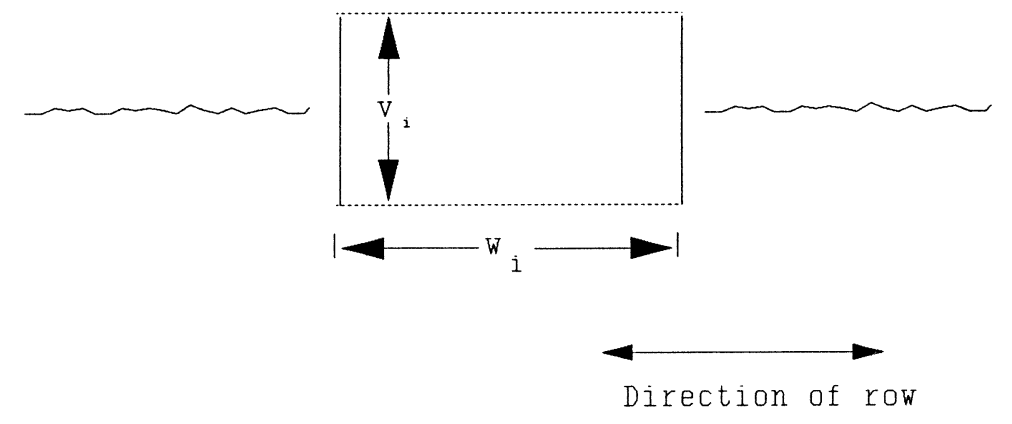

Figure 1. Illustration of the dimensions of the skip object.

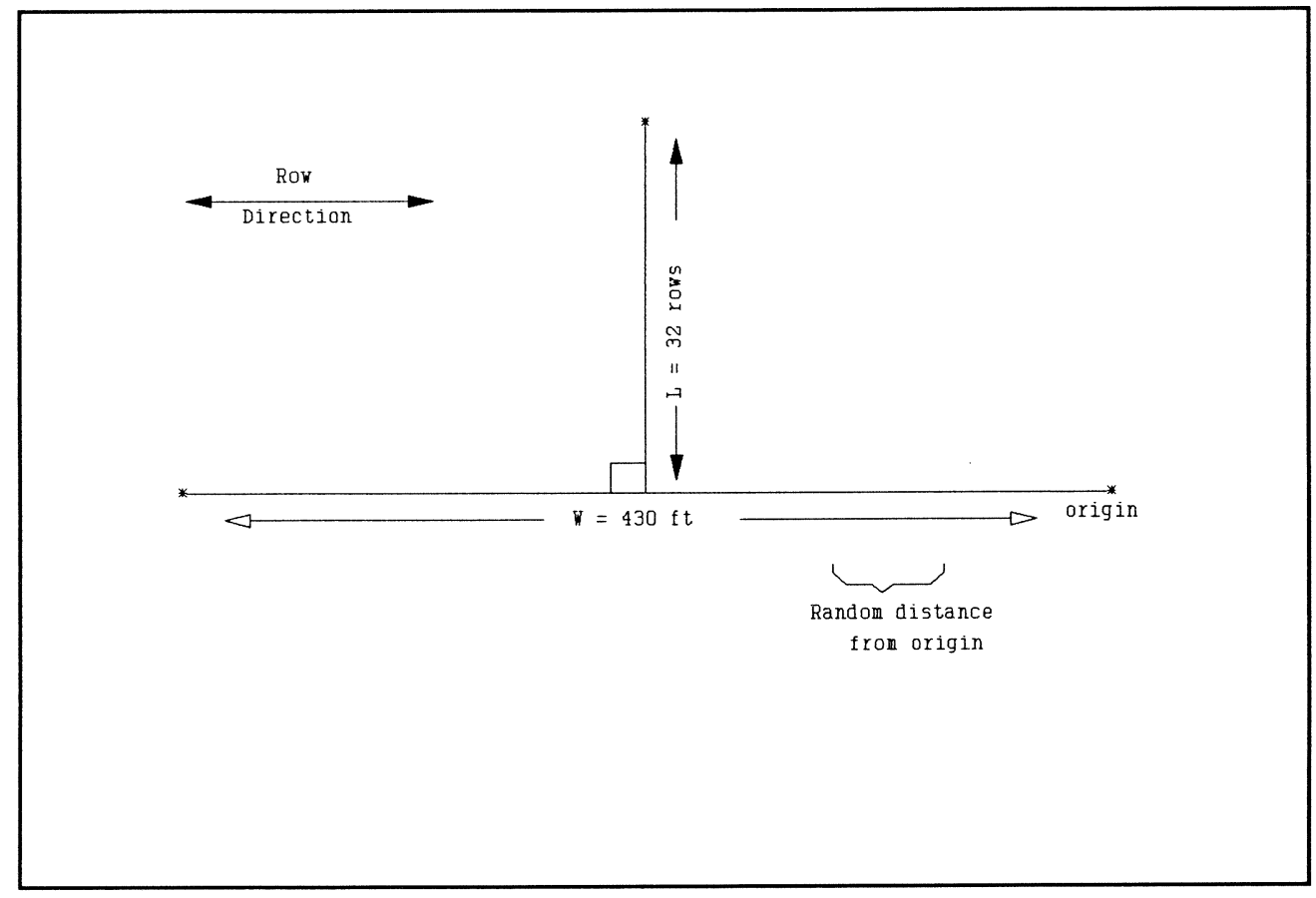

Figure 2. Diagram of the placement of the transect line on the baseline. 


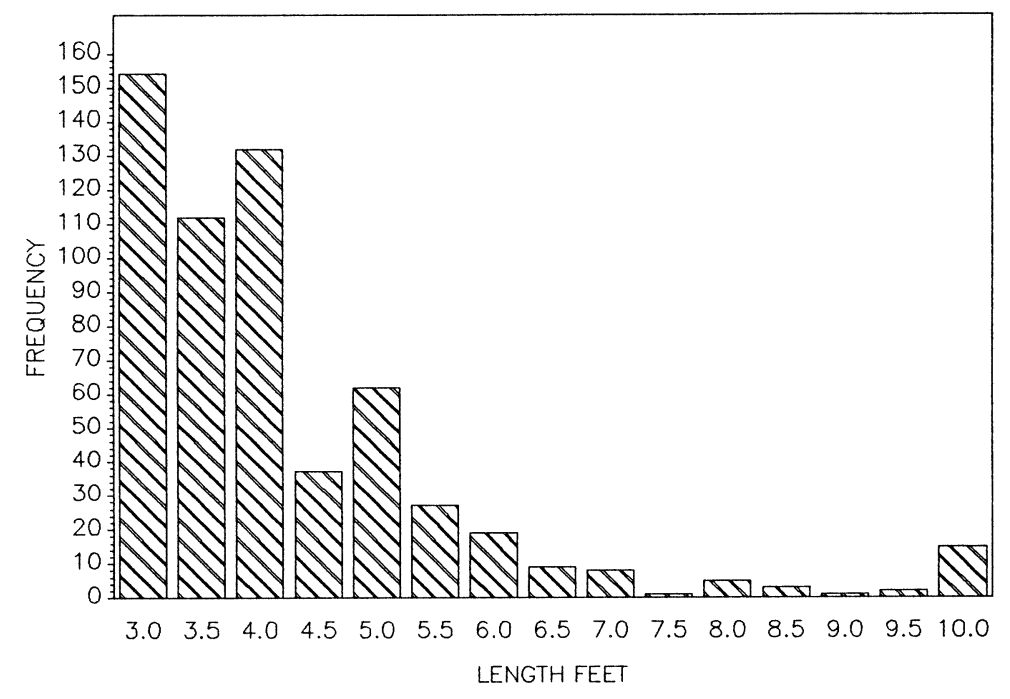

Figure 3. Histogram of skip widths measured in one half of the combined one acre study areas.

Table 1. Estimates for density, mean length, and coverage (percent stand loss) per acre for skips in cotton. The last column lists the mean square error (MSE) for each.

\begin{tabular}{lccccr}
\hline Parameter & $\begin{array}{c}\text { Observer } \\
1\end{array}$ & $\begin{array}{c}\text { Observer } \\
2\end{array}$ & $\begin{array}{c}\text { Observer } \\
3\end{array}$ & $\begin{array}{c}\text { Observer } \\
4\end{array}$ & MSE \\
\hline Density* & 553.92 & 403.74 & 490.90 & 326.35 & 56,626 \\
Mean Length* 4.32 & 3.87 & 3.87 & 4.50 & 1.25 \\
$\begin{array}{l}\text { Coverage* } \quad 17.97 \\
\text { * }\end{array}$ & 10.94 & 13.28 & 10.16 & 51.47 \\
$\begin{array}{l}\text { Density (number per acre) } \\
\text { Mean Length (feet) }\end{array}$ & & & & \\
Coverage (percent)
\end{tabular}

